\title{
PREPARAÇÃO E VALIDAÇÃO DE ARQUIVOS DE ENTRADA PARA USO NO SIMULADOR DE QUALIDADE DO AR (CMAQ)
}

\author{
Rodrigo do P. Maia ${ }^{\mathrm{a}, *, \odot}$, Leonardo Baptista ${ }^{\mathrm{a}, \mathrm{b}}$ e Eduardo Monteiro Martins ${ }^{\mathrm{a}, \mathrm{c}}$ \\ anstituto de Química, Universidade do Estado do Rio de Janeiro, 20550-900 Rio de Janeiro - RJ, Brasil \\ bDepartamento de Química e Ambiental, Faculdade de Tecnologia, 27537-000 Resende - RJ, Brasil \\ 'Departamento de Engenharia Sanitária e do Meio Ambiente, Faculdade de Engenharia, Universidade do Estado do Rio de Janeiro, \\ 20550-900 Rio de Janeiro - RJ, Brasil
}

Recebido em 08/02/2020; aceito em 10/08/2020; publicado na web em 21/09/2020

\begin{abstract}
PREPARATION AND VALIDATION OF INPUT FILES FOR USE IN THE AIR QUALITY SIMULATOR (CMAQ). According to the inventories carried out by the air pollution control agencies, vehicle emissions are responsible for more than $70 \%$ of air pollutants in metropolitan regions. Proper handling of CMAQ input data is an important step in the formation of a database for the model. Thus, it is necessary to insert the meteorological data using the Weather Research and Forecasting (WRF) version 3.9 in the period of the 31 days of January 2013. Four domains with resolutions of 27, 9, 3 and 1 kilometers were used and 21 vertical layers. Spatial Allocator (SA) was used to format the maps and extract the data necessary for the construction of the SMOKE emissions inventory files. WRF was validated comparing the simulation results with data from two weather stations (Jardim Primavera and Nova Iguaçu), using the statistical methods MB, MAGE, RMSE and IOA. SMOKE presented a constant time profile, this occurred because the established hourly function only contemplated daily results without taking into account the variations over the week.
\end{abstract}

Keywords: Air Pollution; WRF; SMOKE; CMAQ.

\section{INTRODUÇÃo}

A poluição atmosférica em centros urbanos é um processo complexo, no qual uma abordagem correta de controle e mitigação deve incluir discussões nas diferentes áreas de conhecimento. Com o crescimento das cidades, ocorre um aumento das emissões de poluentes para atmosfera, em especial o aumento das emissões veiculares. Os inventários de emissões de poluentes atmosféricos indicam que nas grandes metrópoles cerca de 70 a $80 \%$ dos poluentes atmosféricos são provenientes de emissões veiculares. ${ }^{1,2}$

De acordo com dados levantados pelo Instituto Estadual do Ambiente (INEA), 77\% das emissões atmosféricas na Região Metropolitana do Rio de Janeiro (RMRJ) são oriundas de fontes veiculares. ${ }^{3}$ As emissões veiculares (fontes móveis) são provenientes de processos de combustão dos motores, do vazamento e evaporação dos compostos orgânicos voláteis, da frenagem, do desgaste dos pneus, e por ressuspensão das partículas provocadas pela circulação dos veículos nas vias. ${ }^{4}$

Esses poluentes primários sofrem processos físicos e químicos de transformação, transporte pelo vento, deposição seca, deposição úmida e reações químicas. Essas transformações estão relacionadas à qualidade do ar de um determinado local, o qual irá impactar a saúde das populações expostas a estes poluentes. O entendimento da química da atmosfera é fundamental para compreensão dos processos químicos que ocorrem na atmosfera e que levam a formação de poluentes gasosos secundários e ao aerossol orgânico secundário (SOA, secondary organic aerossol). ${ }^{5-7}$

O monitoramento da concentração dos poluentes na atmosfera, o uso de modelos cinéticos e modelos da qualidade do ar estão entre as metodologias utilizadas para descrição da qualidade do ar. ${ }^{8}$ Esses métodos permitem a quantificação e a descrição da distribuição espacial de poluentes atmosféricos, possibilitando que medidas de controle e mitigação da poluição atmosférica sejam tomadas. ${ }^{9,10}$

*e-mail: rodrigopmaia@outlook.com
Em particular, os modelos de qualidade do ar são utilizados para simular as concentrações de poluentes em uma determinada região da atmosfera e estimar seu comportamento. É fundamental o entendimento dos processos de dispersão, diluição devido a condições meteorológicas e à interação com poluentes emitidos por outras fontes. Por esses motivos, os modelos matemáticos são uma ferramenta valiosa que auxiliam na determinação de estratégias de controle das emissões e na preservação da qualidade do ar. A combinação de dados de monitoramento, com os modelos de qualidade do ar é a melhor abordagem para descrição mais realista da atmosfera e, consequentemente, a melhor gestão da qualidade do ar e fomento de políticas ambientais. ${ }^{11-13}$

Diversos estudos com modelos de qualidade do ar para a previsão de poluentes secundários vêm sendo desenvolvidos no Brasil e em especial no Rio de Janeiro. A maioria destes trabalhos utiliza o modelo Ozone Isopleth Package for Research (OZIPR) que é um modelo unidimensional ou em "caixa", que avalia a contribuição dos compostos orgânicos na formação de ozônio, sem que haja a necessidade de descrever a distribuição espacial dos parâmetros físicos e químicos. $\mathrm{O}$ modelo OZIPR foi desenvolvido pela agência americana de proteção ambiental, United States Environmental Protection Agency (USEPA), e possui descrição física simplificada da atmosfera. A parte química é descrita por um modelo cinético que descreve os processos químicos

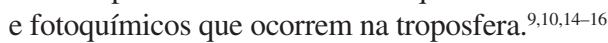

Diferente dos modelos em "caixa" como OZIPR, os modelos de dispersão Gaussianos são normalmente utilizados para representar os processos físicos e detalhar os mecanismos de transporte e deposição. Esses processos estão relacionados diretamente a meteorologia da região estudada. Em geral, eles fazem aproximações simplistas dos processos químicos e, em muitos casos, não consideram a existência de reações químicas durante a dispersão dos poluentes. Esses modelos possuem grande aplicação nos processos de licenciamento ambiental de atividades industriais com alto poder poluidor. ${ }^{17}$

Nos últimos anos, modelos computacionais mais complexos vêm sendo desenvolvidos e aprimorados. Esses modelos buscam 
detalhar tanto os processos físicos como as transformações químicas que ocorrem na troposfera. Diversos trabalhos foram desenvolvidos para descrever a qualidade do ar em grandes cidades do mundo utilizando modelos tridimensionais de qualidade do ar. O modelo Community Multi-Scale Air Quality (CMAQ), desenvolvido pela Universit of North Caroline (UNC) vem ganhando destaque com diversos trabalhos. ${ }^{18-27}$

Entretanto, o uso do CMAQ para simulação da qualidade do ar depende da existência de um modelo matemático que descreva a meteorologia e um processador para a distribuição espacial e temporal das emissões. Por esse motivo, junto ao CMAQ é usado o modelo WRF (Weather Research and Forecasting), ${ }^{28}$ e mais um préprocessador das emissões de poluentes para a atmosfera, o código Sparse Matrix Operator Kernel Emissions (SMOKE). ${ }^{29}$ No caso de algum erro durante a utilização de uma dessas duas ferramentas, por exemplo, erros nas condições meteorológicas ou nas emissões dos poluentes, levará a propagação de erros durante a simulação do modelo químico. ${ }^{12,24,30}$

Logo, as simulações numéricas da qualidade do ar demandam conhecimento do clima da região a ser estudada e da disponibilidade de dados meteorológicos, sendo a obtenção desses dados um dos maiores desafios da modelagem, pois existe grande dificuldade de se obter dados de qualidade de estações meteorológicas e de radiossondagem para grandes regiões. ${ }^{12}$ Além disso, são necessários dados meteorológicos em escala tridimensional para grandes áreas, escritos em arquivos com formatação específica. Por essas razões, existem modelos numéricos para simulação da dinâmica da atmosfera que geram informações necessárias sobre a meteorologia e que podem ser usados a posteriori em modelos de qualidade do ar. ${ }^{31} \mathrm{O}$ modelo numérico de mesoescala WRF é utilizado para gerar esses dados meteorológicos e foi desenvolvido com a parceria de grupos de pesquisa, entre elas o National Center for Atmospheric Research (NCAR), National Oceanic and Atmospheric Administration (NOAA), National Center for Environmental Prediction (NCEP) e outros órgãos de pesquisa e desenvolvimento. ${ }^{25}$

O WRF pode ser aplicado a pesquisas voltadas para previsão do tempo, de parâmetros físicos, na modelagem da qualidade do ar, dispersão de poluentes atmosféricos e estudos comparativos entre cenários hipotético e reais. O modelo permite a parametrização da grade que descreve a área estudada a fim de se adequar o refinamento e nível de precisão desejado no modelo. Cabe ressaltar que quanto maior o refinamento na grade de simulação, maior será o custo computacional para realizar a simulação..$^{23,32}$

O SMOKE é uma ferramenta de processamento de emissões de poluentes atmosféricos como monóxido de carbono (CO), óxidos de nitrogênio $\left(\mathrm{NO}_{\mathrm{x}}\right)$, compostos orgânicos voláteis (COV), amônia $\left(\mathrm{NH}_{3}\right)$, dióxido de enxofre $\left(\mathrm{SO}_{2}\right)$, material particulado de diferentes tamanhos aerodinâmicos $\left(\mathrm{MP}_{10} \mathrm{e} \mathrm{MP}_{2,5}\right)$, bem como um série de poluentes tóxicos como mercúrio, cádmio, benzeno e formaldeído. $\mathrm{O}$ SMOKE faz a espacialização das emissões dos poluentes primários dentro da área de estudo. ${ }^{29}$

O SMOKE foi aplicado à Península Ibérica e a Região de Madri (Espanha) para processar os inventários de emissões da Espanha para os anos de 2000 e $2010 .{ }^{21}$ O SMOKE foi considerado uma ferramenta útil para gerar informações de entrada de emissão para o modelo CMAQ. Este estudo estabeleceu uma metodologia prática para a adaptação do sistema SMOKE à Espanha e potencialmente a qualquer outro país europeu. ${ }^{21}$ Posteriormente, uma versão adaptada às emissões de poluentes do continente Europeu foi desenvolvida (SMOKE-UE) e usado para simulação da concentração de $\mathrm{O}_{3}, \mathrm{NO}_{2}$ e $\mathrm{SO}_{4}{ }^{2-}$ utilizando o CMAQ. ${ }^{33}$

Seguindo a ideia dos trabalhos da literatura, este trabalho tem como objetivo adaptar o sistema WRF/SMOKE ao caso da Região
Metropolitana do Rio de Janeiro (RMRJ) para a modelagem da qualidade do ar em conjunto do modelo CMAQ.

\section{METODOLOGIA}

Os dados meteorológicos necessários para a validação do modelo WRF foram a obtidos nas estações meteorológicas da Secretaria Municipal de Meio Ambiente do Rio de Janeiro (SMAC) e do INEA para o mês de janeiro de 2013.

De acordo com a região que iremos realizar a simulação, é necessário montar uma grade de estudo com domínios aninhados, ou seja, quadrantes que estejam contidos dentro da região de estudo. Esses domínios são importantes para melhorar a qualidade dos resultados do domínio principal. ${ }^{34}$

\section{Grade de estudo}

As simulações meteorológicas foram realizadas utilizando quatro domínios aninhados descritos na Figura 1. O maior domínio (D04) apresenta resolução espacial de $27 \mathrm{~km}$ com 56x56 células, de área total $1512 \times 1512 \mathrm{~km}$ que compreende os estados do Rio de Janeiro, Minas Gerais, São Paulo, Espírito Santo, Paraná, Santa Catarina, Rio Grande do Sul, Goiás e grande parte da Bahia, Tocantins, Mato Grosso, Mato Grosso do Sul e uma pequena parte dos estados do Pará, Maranhão, Piauí e Sergipe. Esse grande domínio possibilitando a captura das condições sinóticas e padrões circulação sobre a área de interesse. O domínio D03 possui resolução de 9 km com 82x82 células totalizando $738 \times 738 \mathrm{~km}$ de área, cobrindo todo estado do Espírito Santo e Rio de Janeiro, grande parte do estado de Minas Gerais e São Paulo, além de pequenas áreas dos estados de Santa Catarina, Paraná e Bahia. O domínio D02 tem $3 \mathrm{~km}$ de resolução com 130x130 células com 390x390 km incluindo em sua área as partes dos estados de São Paulo, Minas Gerais, Espírito Santo e a totalidade do estado do Rio de Janeiro. O domínio D01 é o mais refinado, contendo $1 \mathrm{~km}$ de resolução espacial e 151x82 km área. Esse compreende toda a RMRJ e cidades vizinhas a ela. Os quatro domínios estão centrados nas coordenadas $-22,81^{\circ} \mathrm{S} ;-43,24^{\circ} \mathrm{W}$. Todos os testes de parametrizações foram feitos utilizando a técnica two-way nesting em todos os domínios. ${ }^{25,35,36} \mathrm{~A}$ estrutura vertical foi representada por 21 camadas verticais, distribuídos na proporção de 1,000, 0,998, 0,995, 0,992, 0,988, 0,982, 0,976, 0,970, 0,950, 0,930, $0,870,0,800,0,740,0,630,0,540,0,450,0,360,0,270,0,180,0,090$, 0,000 , sendo que o valor 1,000 representa a camada mais próxima do solo e o valor 0,000 representa a camada mais afastada do solo totalizando $15 \mathrm{~km}$ de distância. As parametrizações físicas utilizadas para a microfísica foi a proposta por Lin, para radiação de onda longa RRTM,${ }^{37}$ para radiação de onda curta Dudia, ${ }^{38}$ para a camada de superfície Monin-Obukhov, ${ }^{39}$ para superfície terrestre Noah, ${ }^{40}$ para camada limite planetária $\mathrm{YSU}^{41}$ e para parametrização de Cumulus foi usado a proposição de Kain-Fristsch. ${ }^{42}$

Após a definição da grade, foi utilizado o modelo WRF versão $4.1,{ }^{28}$ para simular as condições meteorológicas com base em dados meteorológicos globais obtidos fornecidos pela University Corporation for Atmospheric Research(UCAR) em arquivos GRIB2 do National Centers for Environmental Prediction (NCEP). ${ }^{43}$ Foram utilizados dados meteorológicos para os 31 dias do mês janeiro do ano de 2013, e posteriormente os dados resultantes da simulação - temperatura, direção do vento, velocidade do vento e umidade específica - foram comparados com os dados das estações meteorológicas publicados nas páginas do INEA para validação. ${ }^{44,45}$ A qualidade dos dados simulados foi verificada pelos testes estatísticos, Mean Bias (MB), Mean Absolute Gross Error (MAGE), Root Mean Square Error (RMSE) e Index of 


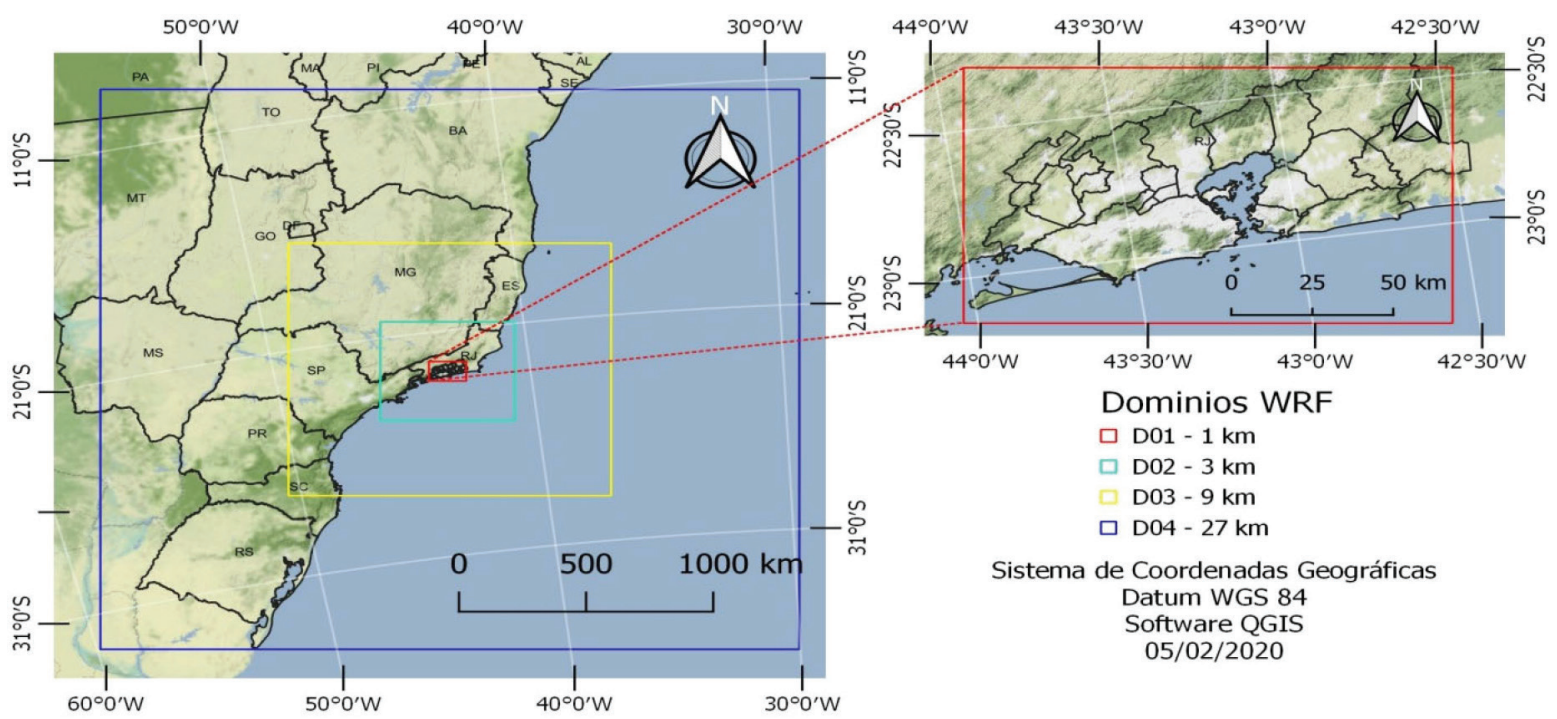

Figura 1. Representação dos domínios criados para simulação da área de estudo. A figura a direita apresenta um detalhamento do domínio D01

Agreement (IOA).$^{46-49}$ Os dados simulados foram obtidos através da ferramenta read_wrf_nc, que realiza a extração dos dados a partir da informação da latitude e longitude onde estão localizadas as estações meteorológicas, e então é criado um arquivo informando os parâmetros físicos e meteorológicos nas células onde estão localizadas as estações.

A função de polarização média (Mean Bias - MB) avalia o acordo entre os valores simulados e os observados, nos quais os valores positivos de $\mathrm{MB}$ significam que os dados simulados estão superestimados e valores negativos indicam que os dados estão subestimados. MB é calculado a partir da Equação 1.47,50

$$
M B=\frac{1}{n} \sum_{i=1}^{n}\left(\varphi_{s i m}-\varphi_{o b s}\right)
$$

$\mathrm{O} \varphi_{\text {obs }}$, corresponde aos valores das variáveis observadas nas estações de monitoramento da qualidade do ar e das estações meteorológicas e, $\varphi_{\text {sim }}$, corresponde aos valores das variáveis obtidas durante a simulações e, n, corresponde ao número de observações.

O Erro Médio Absoluto (Mean Absolute Gross Error - MAGE) é usado para calcular a diferença entre duas variáveis ou o erro médio associado entre os valores simulados e observados. Esse erro é calculado pela Equação $2 .^{25}$

$$
M A G E=\frac{1}{n} \sum_{i=1}^{n}\left|\varphi_{s i m}-\varphi_{o b s}\right|
$$

A Raiz do Erro Quadrático Médio (Root Mean Square Error RMSE) representa a raiz quadrada do erro médio quadrático, que é a média quadrática das diferenças entre os pares de dados simulados e observados, sendo calculado pela Equação $3 .{ }^{51}$

$$
R M S E=\sqrt{\frac{1}{n} \sum_{i=1}^{n}\left(\varphi_{s i m}-\varphi_{o b s}\right)^{2}}
$$

Índice de concordância (Index of Agreement - IOA) serve como uma medida normalizada do grau de erro de previsão do modelo e possui uma variação entre 0 e 1 . Quando o valor obtido se aproxima de 1 temos a indicação de que ocorre uma combinação quase perfeita e quando o valor obtido se aproxima de 0 temos uma indicação de que existe uma forte discordância entre os resultados simulados e os observados (Equação 4). ${ }^{52}$

$$
I O A=1-\left[\frac{\sum_{i=1}^{n}\left(\varphi_{s i m}-\varphi_{o b s}\right)^{2}}{\sum_{i=1}^{n}\left(\left|\varphi_{s i m}-\bar{\varphi}_{o b s}\right|+\left|\varphi_{o b s}-\bar{\varphi}_{o b s}\right|\right)^{2}}\right]
$$

Após a validação dos dados simulados, foram selecionados os períodos do mês de janeiro de 2013, período no qual ocorreram violações da concentração de ozônio, segundo dados do Relatório de qualidade do ar do Instituto Estadual do Ambiente. ${ }^{3}$

Os resultados obtidos com o modelo WRF foram pré-processados com o intuito de serem introduzidos no processador de emissões SMOKE e futuramente no modelo de qualidade do ar CMAQ. Por meio do processador de Interface Meteorológica e Química (Meteorology - Chemistry Interface Processor (MCIP) ${ }^{53}$ foi realizada a mudança dos formatos de dados, conversão das unidades de medida. O MCIP realizou ainda a extração dos dados do domínio meteorológico, além de realizar a alteração no tamanho da grade para o WRF, fazendo a redução na proporção adequada para a entrada no modelo fotoquímico, ${ }^{53}$ como pode ser visto na Figura 1S. Dessa forma, ele é capaz de reconstruir toda a grade horizontal e a grade vertical por meio de interpolações, quando necessário, ou realizar o cálculo dos parâmetros meteorológicos faltantes, necessários para a realização das simulações com modelo CMAQ. ${ }^{54}$

$\mathrm{O}$ MCIP gerou nove arquivos que foram utilizados no programa de alocação espacial (Spatial Allocator (SA) para a conversão de mapas para o formato desejado. Também foi realizada a extração de dados referentes a cada célula e criação do arquivo de linha da costa oceânica. O SA também foi utilizado associado ao SMOKE para fazer a alocação espacial referente aos tipos de emissões antropogênicas. Dentre os arquivos gerados pelo MCIP, está o GRIDDESC, que contém a grade de trabalho para o CMAQ. Após o uso do SA, a grade que havia sido definida para o WRF com dimensões de 151x82 km, foi diminuída para $138 \times 69 \mathrm{~km}$.

Ao escolher um período de modelagem, é necessário ter um intervalo de tempo spin-up antes do início do tempo ao qual se deseja simular no CMAQ. O período de spin-up é uma sequência de dias no início de uma simulação da qualidade do ar que não é usada na análise dos resultados da modelagem. Esses dias são simulados para minimizar os impactos das condições iniciais nos resultados da modelagem no CMAQ. Os períodos de spin-up variam com o tamanho do domínio de modelagem, da magnitude das fontes de emissões e dos poluentes em estudo. Como regra geral, um período de pelo menos 
10 dias deve ser considerado por um período de spin-up, ${ }^{55}$ para uma resolução de grade de $12 \times 12 \mathrm{~km}$. Para esse estudo de estudo com uma grade de resolução de $1 \times 1 \mathrm{~km}$ o período de spin-up adotado foi de 1 dia.

\section{Processamento do inventário de fontes móveis}

Para realizar as simulações com o SMOKE foi necessário o tratamento dos dados dos inventários de emissões. Não existe um banco de dados e nem ferramentas que permitam a otimização das etapas de inserção de dados do cenário nacional, ${ }^{4}$ assim como existe para o modelo americano.

Na preparação dos arquivos de entrada do SMOKE, existem procedimentos a serem seguidos. para descrição das emissões por fontes veiculares (fontes móveis) e para fontes área. As fontes área englobam todo tipo de fontes emissoras que façam parte de uma área, seja ela fonte fixa (indústrias), fontes móveis, fontes residenciais e comerciais, sendo necessário criar arquivos que contenham informações do país, código da região (COSTCY), código do tipo de fonte (SCC) e codificação do tipo de poluente que o veículo emite.

Dessa forma, todo trabalho de entrada de dados foi feito de forma manual obedecendo a estrutura descrita nos manuais de usuário. ${ }^{29}$ No caso do inventário de fontes móveis e das fontes área foi necessário a preparação dos códigos de referência cruzada (COSTCY e SCC). Para criação do código COSTCY, para a RMRJ, ${ }^{21,24}$ foi criada uma codificação de referência para a região como pode ser visto na Tabela 1.

O segundo passo foi a criação dos códigos de referência dos tipos de fontes (SCC). O padrão para o inventário de fontes móveis é um código de 10 dígitos, sendo que cada 2 dígitos fazem referência a um tipo específico de informação. Os dois primeiros dígitos se referem às fontes móveis (por padrão a numeração começa com 22), tipo de combustível, tipo de veículo, tipo de rodovia e tipo de processo, respectivamente. No caso dos tipos de combustíveis foi adotado a codificação "x2" para os veículos a gasolina, etanol e flex, visto que o modelo não possui um padrão para motores que consumam apenas etanol puro, além disso a gasolina no padrão brasileiro contém até $27 \%$ de etanol. ${ }^{56}$ Os códigos 11, 21, 32, 41, 42 e 72 foram adotados para motos, automóveis, ônibus rodoviário, ônibus urbano, veículos comerciais leves, veículos pesados, respectivamente. O código 02 foi adotado para os veículos movidos a Diesel. ${ }^{29}$

As emissões veiculares foram divididas em dois grupos, no primeiro estão as rodovias de maior tráfego veicular que foram classificadas como em vias expressas (código 04). No outro grupo, denominado de demais vias (código 05), foram incluídas as vias secundárias, arteriais e locais. Os dois grupos foram tratados como fontes emissoras lineares (fontes linha). Ainda houve a separação das emissões de veículos leves, pesados e tipo de combustível utilizado. O código 50 foi adotado, pois este permite agrupar todos os processos de exaustão em apenas um código. A definição dos códigos utilizados pode ser vista na Tabela $1 \mathrm{~S}$.

Após a codificação, é possível criar o arquivo com dados do inventário de fontes móveis por meio dos dados brutos do Inventário de Fontes Móveis da Região Metropolitana do Rio de Janeiro tendo como referência o ano de $2013 .{ }^{4}$ Foi criado o arquivo "mbinv.txt", que é o arquivo de entrada de dados do inventário para o SMOKE. Nesse arquivo é necessário informar o COSTCY, o SCC, o percentual do poluente emitido de acordo com o SCC e o código do poluente. O próximo passo para que estes dados possam ser interpretados pelo SMOKE é a conversão das informações geográficas de latitude e longitude em coordenadas cartesianas (x,y).

A conversão é feita usando o arquivo control_variable_grid. $c s v$ fornecido pelo SA. Nesse arquivo, a localização dos arquivos de

Tabela 1. Código COSTCY criado para o desenvolvimento do trabalho

\begin{tabular}{|c|c|c|c|c|c|c|}
\hline País & Código & Estado & Código & Município & Código & COSTCY \\
\hline Brasil & 7 & Rio de Janeiro & 33 & Belford Roxo & 456 & 733456 \\
\hline Brasil & 7 & Rio de Janeiro & 33 & Cachoeira de Macacu & 803 & 733803 \\
\hline Brasil & 7 & Rio de Janeiro & 33 & Duque de Caxias & 702 & 733702 \\
\hline Brasil & 7 & Rio de Janeiro & 33 & Guapimirim & 850 & 733850 \\
\hline Brasil & 7 & Rio de Janeiro & 33 & Itaboraí & 900 & 733900 \\
\hline Brasil & 7 & Rio de Janeiro & 33 & Itaguaí & 007 & 733007 \\
\hline Brasil & 7 & Rio de Janeiro & 33 & Japeri & 270 & 733270 \\
\hline Brasil & 7 & Rio de Janeiro & 33 & Magé & 502 & 733502 \\
\hline Brasil & 7 & Rio de Janeiro & 33 & Maricá & 700 & 733700 \\
\hline Brasil & 7 & Rio de Janeiro & 33 & Mesquita & 858 & 733858 \\
\hline Brasil & 7 & Rio de Janeiro & 33 & Nilópolis & 203 & 733203 \\
\hline Brasil & 7 & Rio de Janeiro & 33 & Niterói & 302 & 733302 \\
\hline Brasil & 7 & Rio de Janeiro & 33 & Nova Iguaçu & 500 & 733500 \\
\hline Brasil & 7 & Rio de Janeiro & 33 & Paracambi & 609 & 733609 \\
\hline Brasil & 7 & Rio de Janeiro & 33 & Queimados & 144 & 733144 \\
\hline Brasil & 7 & Rio de Janeiro & 33 & Rio Bonito & 300 & 733300 \\
\hline Brasil & 7 & Rio de Janeiro & 33 & Rio de Janeiro & 557 & 733557 \\
\hline Brasil & 7 & Rio de Janeiro & 33 & São Gonçalo & 904 & 733904 \\
\hline Brasil & 7 & Rio de Janeiro & 33 & São João de Meriti & 109 & 733109 \\
\hline Brasil & 7 & Rio de Janeiro & 33 & Seropédica & 554 & 733554 \\
\hline Brasil & 7 & Rio de Janeiro & 33 & Tanguá & 752 & 733752 \\
\hline
\end{tabular}


saída do MCIP, contendo as informações da grade (GRIDDESC) e as informações da localização dos diretórios onde encontram-se os mapas nos formatos adequados, devem ser informados. A criação da grade ocorrerá depois do preenchimento dos arquivos necessários. Nesse mesmo arquivo são criados pontos em coordenadas cartesianas para leitura do SMOKE, visto que este interpreta apenas dados em formato matricial. Ele é formado por informações da posição da via e do percentual de poluente que é emitido por cada trecho da via. As etapas descritas anteriormente são fundamentais para a criação das tabelas de referência cruzada do SMOKE.

No caso do Brasil, o modelo para descrição das fontes móveis tem limitações, pois o utilitário MOVES do SMOKE só funciona para o modelo desenvolvido para os Estados Unidos devido a problemas de formatação dos arquivos. A mudança na formatação dos arquivos leva à mudança na referência geográfica, o que demandam modificações nos arquivos preparados para o caso brasileiro. Por esse motivo, o arquivo que descreve as fontes móveis (mbinv.txt) teve que ser modificado para um arquivo que descreve fontes áreas (arinv.txt). Com essa modificação, cada trecho de via passou a ocupar um percentual do espaço na grade e as emissões que no arquivo de fontes móveis que estavam em gramas por hora foram alteradas para toneladas por ano. Inicialmente foi feita apenas a inserção dos dados das rodovias contidas no município do Rio de Janeiro, visto que alguns trechos das vias fornecidas no inventário de fontes móveis continham pontos fora do domínio. Os dados do inventário foram adicionados ao programa Quantum GIS, ${ }^{57}$ através das coordenadas UTM contidas nele.

\section{Perfil temporal}

Outra etapa importante na criação dos bancos de dados do SMOKE é a criação de um perfil temporal na forma de arquivos que serão lidos pelo SMOKE. Esses arquivos foram gerados através da função horária de tráfego considerando uma via de tráfego intenso, a partir das informações obtidas no inventário de emissões de fontes veiculares da região metropolitana do Rio de Janeiro ano base de 2013. ${ }^{4}$ A equação 5 descreve a função horária, onde t representa as horas, em termos percentuais da variação da frota $(F)$ ao longo de um dia. ${ }^{4}$

$\mathrm{F}(\mathrm{t})=-4 \mathrm{E}-08 \mathrm{t}^{6}+3 \mathrm{E}-06 \mathrm{t}^{5}-6 \mathrm{E}-05 \mathrm{t}^{4}+0,0004 \mathrm{t}^{3}+0,0009 \mathrm{t}^{2}-$ $-0,0104 t+0,0224$

Com base nos valores gerados pela equação 5 foi criado uma codificação chamada de 2013rj para o arquivo temporal. Essa codificação é utilizada no arquivo atref.txt para buscar o perfil horário das emissões no arquivo atpro_hourly.csv.

\section{Especiação química}

Para a modelagem com o CMAQ é necessário informar as espécies químicas emitidas pelas fontes de acordo com o modelo químico a ser utilizado. Dessa forma, é necessário obter dados de especiação química, seja por meio de estudo das espécies ou por meio de dados da literatura. Sendo assim, após realizado a seleção das espécies, deve-se escolher o modelo químico ao qual irá realizar a simulação. Nesse estudo foi escolhido o modelo químico SAPRAC99 e os dados da especiação química utilizados nos modelos foram obtidos na literatura. ${ }^{14}$ A Tabela 2 mostra os percentuais das concentrações das espécies químicas agrupadas no modelo químico SAPRC99.58,59 O agrupamento do modelo SAPRAC99 é feito pela reatividade dos compostos com o radical $\mathrm{OH}$, compostos com reatividade próxima fazem parte do mesmo grupo. A Tabela 3 mostra o agrupamento dos compostos químicos e a Tabela $2 \mathrm{~S}$ apresenta os compostos químicos pertencentes aos grupos do SAPRC $99 .^{58,59}$

Tabela 2. Percentual de COV adotado para o mecanismo SAPRC99

\begin{tabular}{cc}
\hline Espécies ou Grupos & Percentual de COV \\
\hline Alcanos 2 (ALK 2) & $1,85 \%$ \\
Alcanos 3 (ALK 3) & $20,76 \%$ \\
Alcanos 4 (ALK 4) & $43,18 \%$ \\
Alcanos 5 (ALK 5) & $13,19 \%$ \\
Olefinas 1 (OLE 1) & $0,71 \%$ \\
Olefinas 2 (OLE 2) & $0,36 \%$ \\
Aromáticos 1 (ARO 1) & $5,80 \%$ \\
Aromáticos 2 (ARO 2) & $4,00 \%$ \\
Formaldeído (HCHO) & $1,23 \%$ \\
Acetaldeído (CCHO) & $8,49 \%$ \\
Isopreno (ISOP) & $0,45 \%$ \\
\hline
\end{tabular}

\section{RESULTADOS E DISCUSSÃO}

\section{Inserção das vias na Região Metropolitana do Rio de Janeiro}

A inserção dos dados obtidos nas tabelas do inventário de fontes móveis da RMRJ, demonstrou haver erros de georreferenciamento. Como pode ser visto na Figura 2a, houve a necessidade de ajustar esses dados, pois muitos pontos estavam localizados fora da grade.

A Figura $2 \mathrm{~b}$ mostra as vias inventariadas apenas na cidade do Rio de Janeiro após o descarte das vias com georreferenciamento errados. Essas vias foram alocadas espacialmente com coordenadas

Tabela 3. Agrupamento dos COV de acordo com o modelo SAPRC99

\begin{tabular}{|c|c|c|c|}
\hline Grupo & Número Médio de Carbonos & Tipo de compostos & $\begin{array}{c}\mathrm{kOH} * \\
\mathrm{ppm}^{-1} \mathrm{~min}^{-1} \\
\end{array}$ \\
\hline ALK 1 & 1,000 & Alcanos e outros não aromáticos & $<5 \times 102$ \\
\hline ALK 2 & 3,000 & Alcanos e outros não aromáticos & entre $5,0 \times 102$ e $2,5 \times 103$ \\
\hline ALK 3 & 4,127 & Alcanos e outros não aromáticos & entre $2,5 \times 103$ e $5,0 \times 103$ \\
\hline ALK 4 & 5,361 & Alcanos e outros não aromáticos & entre $5,0 \times 103$ e $1 \times 104$ \\
\hline ALK 5 & 7,732 & Alcanos e outros não aromáticos & $>1 \times 104$ \\
\hline OLE 1 & 4,000 & Alquenos & $<7 \times 104$ \\
\hline OLE2 & 4,685 & Alquenos & $>7 \times 104$ \\
\hline ARO 1 & 7,277 & Aromáticos & $<2 \times 104$ \\
\hline ARO 2 & 8,189 & Aromáticos & $>2 \times 104$ \\
\hline
\end{tabular}


a)

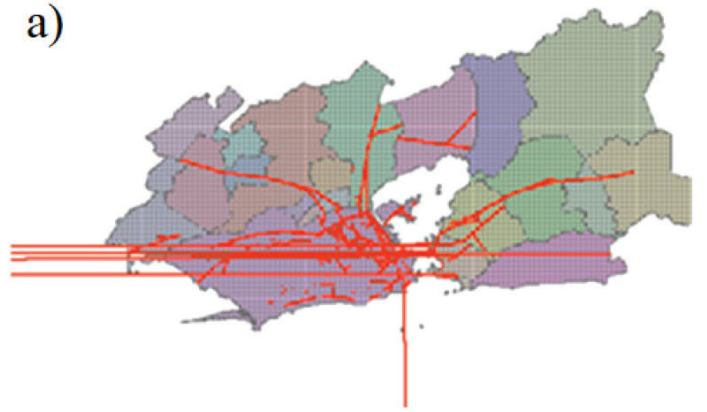

b)

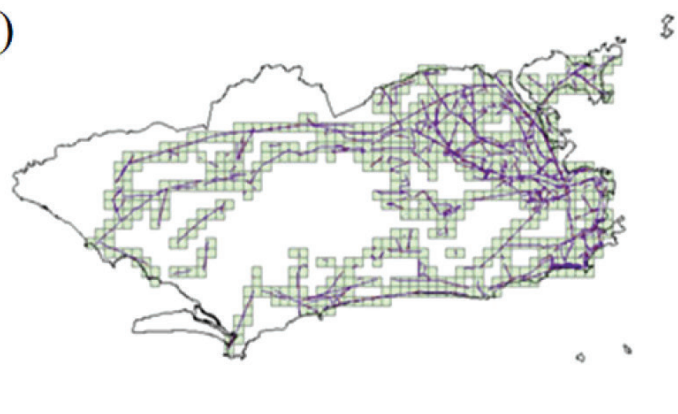

Figura 2. (a) Vias do inventário de fontes móveis na RMRJ no ano 2013. (b) Vias do inventário de fontes móveis na cidade do Rio de Janeiro no ano 2013 obtidas após correção no georreferenciamento

cartesianas. $\mathrm{O}$ arquivo gerado com as de fontes área não discrimina as fontes emissoras.

\section{Validação do WRF}

A Tabela 4 mostra os resultados obtidos da validação do WRF no domínio de maior resolução, D04. Foram comparados os resultados da simulação com WRF com os dados obtidos das estações meteorológicas localizadas em Nova Iguaçu (NI-Monteiro Lobato) e no Jardim Primavera (DC-Jardim Primavera), estas estações foram selecionadas, pois eram as que possuíam a maior quantidade de dados coletados no período selecionado para a simulação.

As Figuras 3a e 3b, mostram os perfis de temperaturas simulados e observados nas estações DC-Jardim Primavera e NI-Monteiro Lobato no período de 1 a 27 de janeiro de 2013. Os desvios apresentados em relação aos critérios estabelecidos para validação do modelo WRF estão dentro dos valores aceitáveis $( \pm \leq 2,00 \mathrm{~K})$ para o método estatístico MAGE, nos quais os valores obtidos foram de 0,39 e 0,34 K para a estação Jardim Primavera e para a estação de Nova Iguaçu, respectivamente. Para o método estatístico $\mathrm{MB}$, o valor do desvio obtido para o Jardim primavera foi de 0,37 . Esse valor positivo significa que os dados médios medidos nas estações meteorológicas apresentaram valores inferiores aos dados modelados. Para Nova Iguaçu, o valor do desvio obtido foi de $-0,31$, o que significa que as medições das estações apresentam valores superiores aos valores simulados. Esses valores estão dentro do aceitável para o modelo que é de $\pm \leq 0,5 \mathrm{~K}$. Já para o método IOA, os valores obtidos foram de 0,88 e 0,89 para as estações de Jardim Primavera e Nova Iguaçu, respectivamente.

Nas Figuras 3a, 3b, 4a e 4b é possível observar os períodos de estabilização (spin-up) do modelo durante os três primeiros dias. Nesse período existem discrepâncias na modelagem da temperatura e da umidade relativa tanto para a estação Jardim Primavera quanto para a estação Nova Iguaçu. Os resultados da simulação da umidade relativa, apresentaram resultados superestimados entre os dias $10 \mathrm{e}$ 12, e subestimados nos dias 10, 12, 17, 19 e 21 como apresentado nas Figuras $4 \mathrm{a}$ e $4 \mathrm{~b}$. As simulações são feitas a partir de séries históricas dos dados meteorológicas e devido à complexidade dos fatores envolvidos podem ocorrer desvios entre dados simulados e experimentais, mas seguindo a avaliação dos parâmetros estatísticos, os resultados podem ser considerados satisfatórios.

Como observado na Tabela 4, o único parâmetro meteorológico que não foi bem calculado pelo WRF foi a velocidade do vento na região de Nova Iguaçu. Para o método estatístico $\mathrm{MB}$, os desvios deveriam ser menores que 0,5 e o valor calculado foi de 0,89 . Os resultados indicam uma superestimativa dos valores simulados em relação ao medido pelas estações meteorológicas. Características locais influenciam esses resultados: a estação Jardim Primavera está localizada em uma área sem grandes interferências das construções urbanas, já a estação de Nova Iguaçu está situada no centro da cidade de Nova Iguaçu e diversos fatores de micro meteorologia local podem interferir na medição dos dados dessa estação. De acordo com os resultados das Figuras 3a, 3b, 4a, 4b e da Tabela 4, o modelo WRF foi corretamente adaptado ao cenário da RMRJ.

\section{Resultados SMOKE}

A Figura 5 mostra a variação da emissão de $\mathrm{CO}$ ao longo do dia, mostrando os pontos e os horários nos quais ocorreram as maiores emissões de CO, na cidade do Rio de Janeiro em função das vias inventariadas.

Como é possível observar, o horário de maior pico ocorreu às 18 horas (Figura 5d), na localização da célula 69x39, posicionada no entroncamento entre a Linha Vermelha e a Avenida Brasil, próximo

Tabela 4. Resultados das comparações estatísticas para validação do WRF

\begin{tabular}{|c|c|c|c|c|}
\hline Parâmetro Meteorológico & Modelo Estatístico & Valor Aceitável & Jardim Primavera & Nova Iguaçu \\
\hline \multirow{3}{*}{ Temperatura } & $\mathrm{MB}(\mathrm{K})$ & $-0,50<x<+0,50$ & 0,37 & $-0,31$ \\
\hline & $\operatorname{MAGE}(\mathrm{K})$ & $\leq 2,00$ & 0,39 & 0,34 \\
\hline & IOA & $\geq 0,80$ & 0,88 & 0,89 \\
\hline \multirow{2}{*}{ Velocidade do Vento } & $\mathrm{MB}\left(\mathrm{m} \mathrm{s}^{-1}\right)$ & $-0,50<x<+0,50$ & 0,49 & 0,89 \\
\hline & $\operatorname{RMSE}\left(\mathrm{m} \mathrm{s}^{-1}\right)$ & $\leq 2,00$ & 1,55 & 1,57 \\
\hline \multirow{2}{*}{ Direção do Vento } & $\operatorname{MB}\left({ }^{\circ}\right)$ & $-10,00<x<+10,00$ & 7,33 & $-8,81$ \\
\hline & $\operatorname{MAGE}\left(^{\circ}\right)$ & $\leq 30,00$ & 27,94 & 29,32 \\
\hline \multirow{3}{*}{ Umidade Específica } & $\operatorname{MB}\left(\mathrm{g} \mathrm{kg}^{-1}\right)$ & $-1,00<x<+1,00$ & 0,04 & 0,06 \\
\hline & $\operatorname{MAGE}\left(\mathrm{g} \mathrm{kg}^{-1}\right)$ & $\leq 2,00$ & 0,01 & 0,01 \\
\hline & IOA & $\geq 0,60$ & 0,68 & 0,67 \\
\hline
\end{tabular}



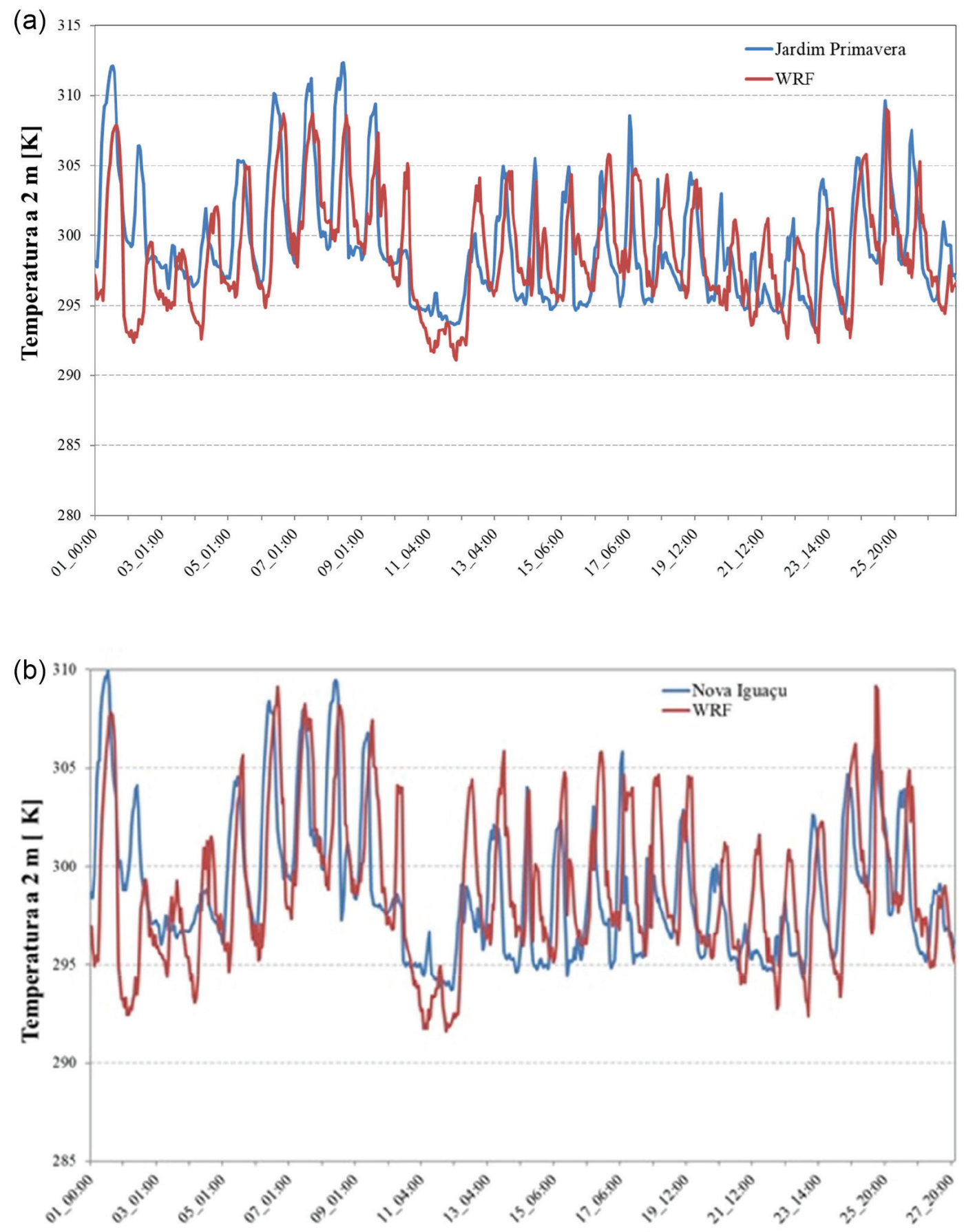

Janeiro de 2013

Figura 3. (a) Comparação entre as temperaturas observadas na Estação meteorológica de Jardim Primavera e simuladas pelo WRF para o local, (b) Comparação entre as temperaturas observadas na estação meteorológica de Nova Iguaçu e simuladas pelo WRF para o local

ao bairro do Caju, Rio de Janeiro. Foi observado o valor máximo de emissão de 62,366 mol s${ }^{-1}$ para o CO. A análise das figuras mostra que, ao longo de todo o dia, o entroncamento entre a Linha Vermelha e a Avenida Brasil apresenta as maiores concentrações de $\mathrm{CO}$ em relação as outras regiões inventariadas.

A Figura 6 apresenta o perfil da distribuição média horária das emissões de CO entre os dias 1 e 10 de janeiro de 2013, emitido por fontes veiculares. O gráfico foi construído considerando todas as fontes inventariadas no presente estudo. Os valores máximos são observados às 18 horas e foram de $0,55 \mathrm{~mol} \mathrm{~s}^{-1}$. Esse resultado aponta que existe um maior número de veículos trafegando no início da noite, horário no qual maior parte da população está retornando para casa após a jornada de trabalho.

$\mathrm{O}$ pico das emissões de $\mathrm{NO}, \mathrm{NO}_{2}, \mathrm{SO}_{2}$ e $\mathrm{MP}_{10}$ ao longo do dia também ocorreu às 18 horas na célula $69 \times 39$, proximidades do bairro do Caju. As emissões máximas foram de 25,066 mol s${ }^{-1}$, $16,347 \mathrm{~mol} \mathrm{~s}^{-1}, 1,165 \mathrm{~mol} \mathrm{~s}^{-1}$ e 26,762 $\mathrm{g} \mathrm{s}^{-1}$ respectivamente para o $\mathrm{NO}, \mathrm{NO}_{2}, \mathrm{SO}_{2}$ e $\mathrm{PM}_{10}$. Esses resultados estão mostrados no Material Suplementar, Figuras 2S, 3S, 4S e 5S. Os resultados para emissão de poluentes lembram uma função periódica bem comportada, devido à dependência das emissões com a frota veicular. Como a dependência da frota veicular com o tempo é dada por uma função polinomial simples, todos os dias da semana apresentam o mesmo perfil de emissão de poluentes. 
(a)
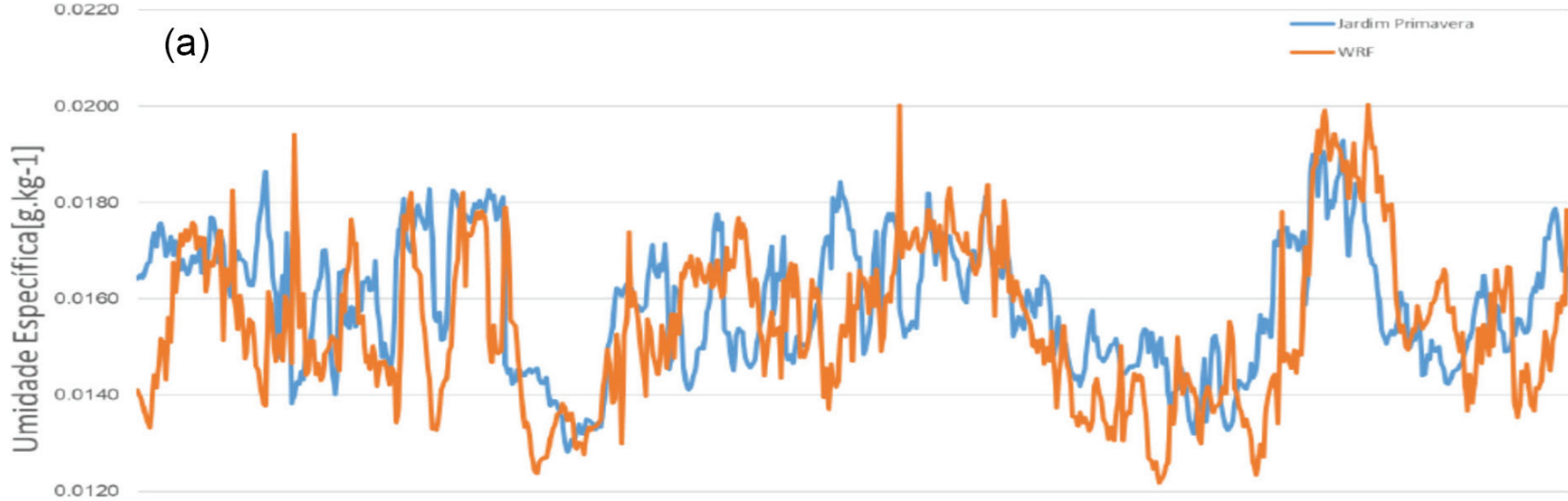

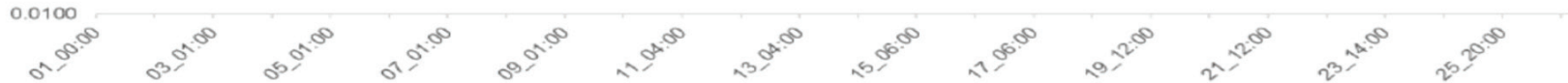

Janeiro de 2013

0.022

(b)

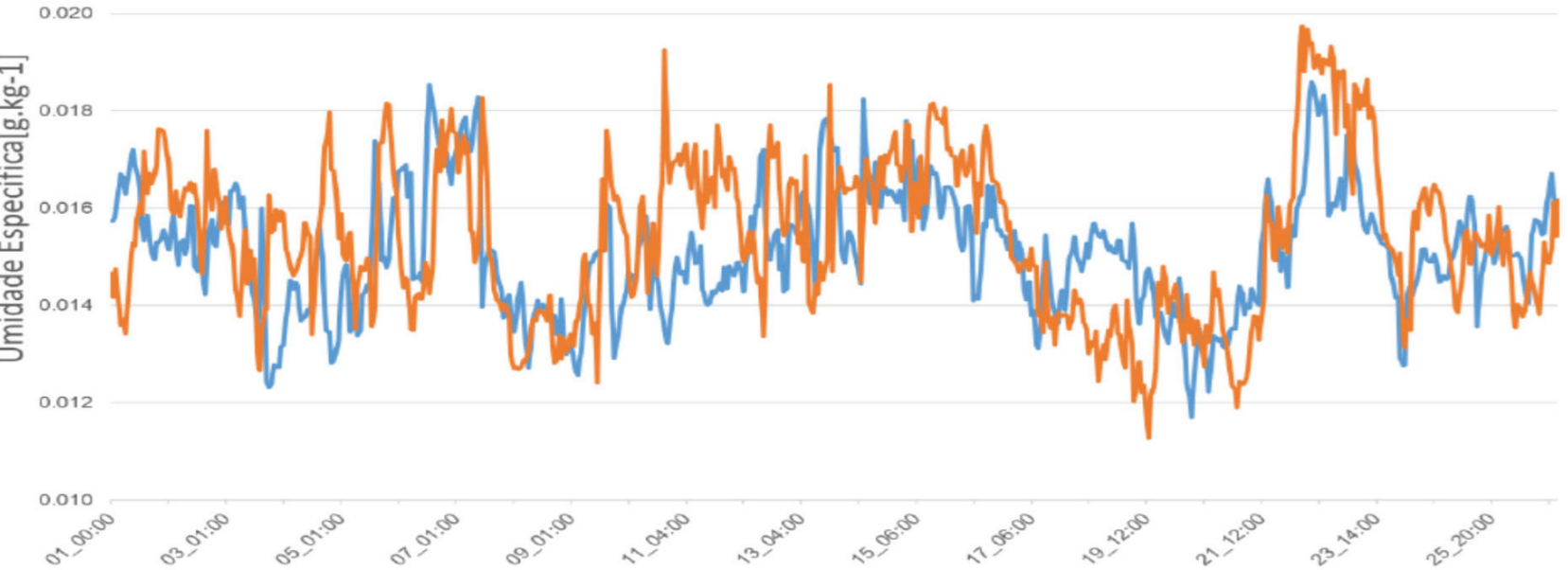

Janeiro de 2013

Figura 4. (a) Comparação entre a umidade específica observadas na estação meteorológica de Jardim Primavera e simuladas pelo WRF para o local, (b) Comparação entre a umidade específica observadas na estação meteorológica de Nova Iguaçu e simuladas pelo WRF para o local

Os resultados das simulações corroboram nossa experiência diária que a qualidade do ar piora ao longo do dia, devido à maior movimentação de veículos, e que o pico de emissões de poluentes ocorre na hora do rush do retorno do trabalho. Pode-se considerar que a implementação dos códigos WRF/SMOKE para RMRJ foi realizada de forma correta, visto que o erro estatístico das simulações está dentro do intervalo aceitável e o pico de emissão de poluentes ocorre no horário de tráfego mais intenso na cidade.

\section{CONCLUSÕES}

A utilização de modelos de qualidade do ar vem se tornando cada vez mais uma ferramenta fundamental para a gestão da qualidade do ar em centros urbanos, assim como para o entendimento dos processos químicos. Entretanto, além de boas medidas das concentrações dos poluentes atmosféricos é de fundamental importância a boa inserção de dados meteorológicos e dados de emissão espacializados.

Os resultados das simulações realizadas com o WRF mostram que esse código foi corretamente adaptado ao cenário da RMRJ, visto que o erro estatístico das simulações está dentro do intervalo aceitável.

A distribuição das emissões feita pelo SMOKE mostra que a célula 69x39, localizada próximo à linha vermelha e à Avenida Brasil, apresentaram os maiores valores para todos os poluentes avaliados.

A emissão dos poluentes é representada por uma função polinomial simples e apresenta o mesmo perfil para todos os dias da semana, para todos os poluentes. Em trabalhos futuros, a descrição da oscilação das emissões em função do tempo deve ser melhorada, pois deve ser levada em consideração a diferença do fluxo veicular entre os dias de semana e os dias do final de semana, para que os resultados representem melhor a dinâmica da área de estudo.

\section{MATERIAL SUPLEMENTAR}

Algumas imagens dos sistemas utilizados neste trabalho estão disponíveis em http://quimicanova.sbq.org.br, na forma de arquivo PDF, com acesso livre. 


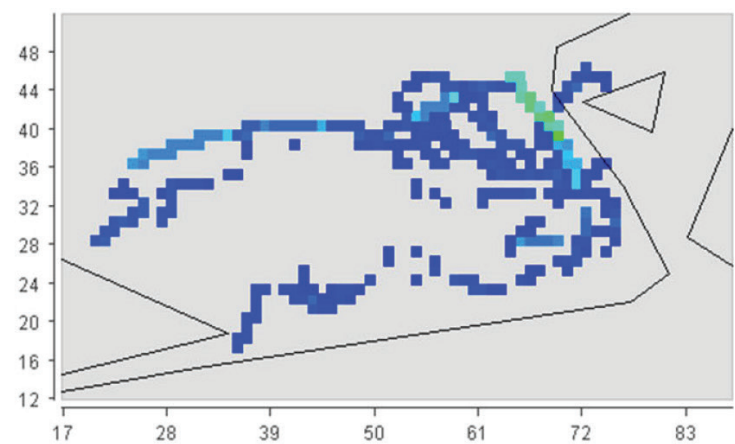

a)

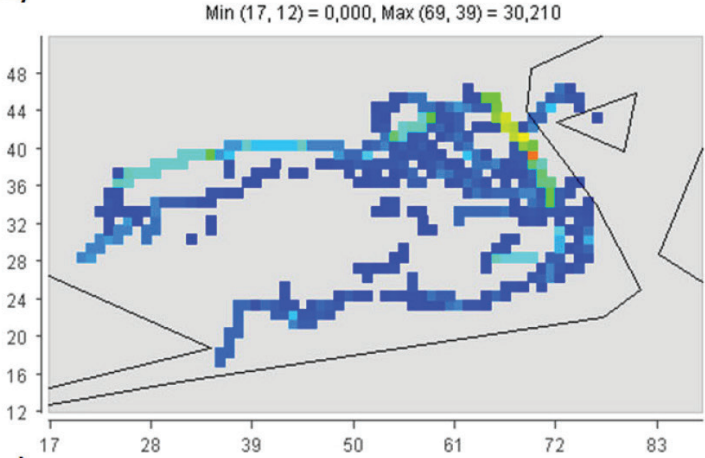

c)

2 de Janeiro de 2013 16:00:00 $\mathrm{h}$ $\operatorname{Min}(17,12)=0,000, \operatorname{Max}(69,39)=58,789$

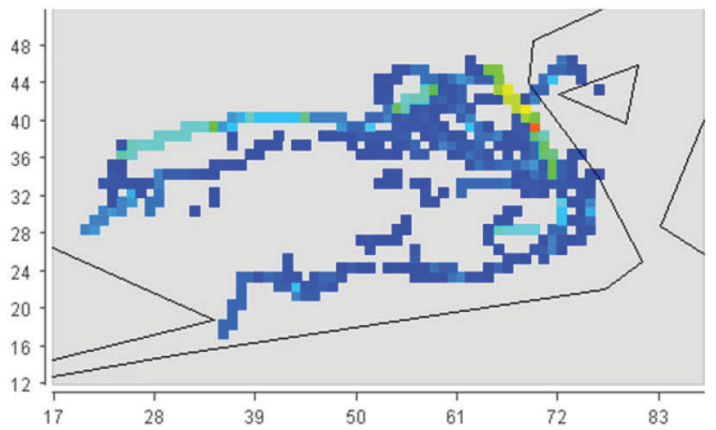

e)

2 de Janeiro de 2013 20:00:00 $\mathrm{h}$ $\operatorname{Min}(17,12)=0,000, \operatorname{Max}(69,39)=60,062$
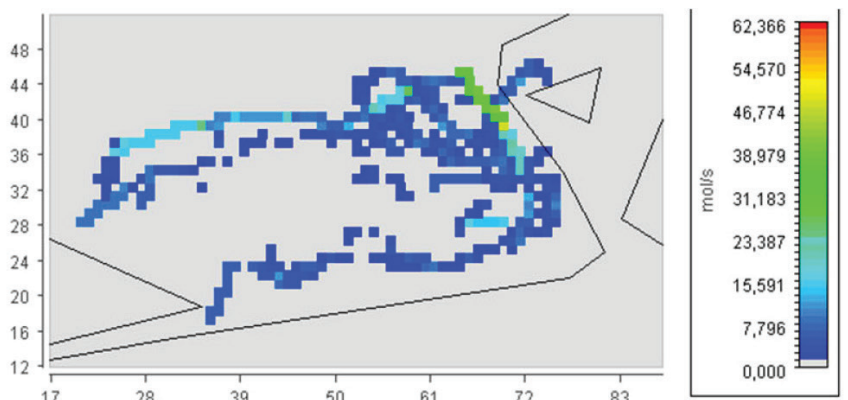

b)

2 de Janeiro de $201314: 00: 00 \mathrm{~h}$ $\operatorname{Min}(17,12)=0,000, \operatorname{Max}(69,39)=47,624$
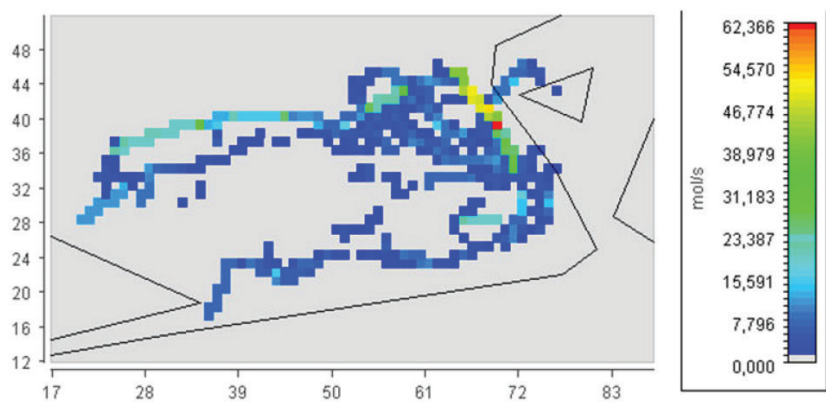

d)

$\operatorname{Min}(17,12)=0,000, \operatorname{Max}(69,39)=62,36$

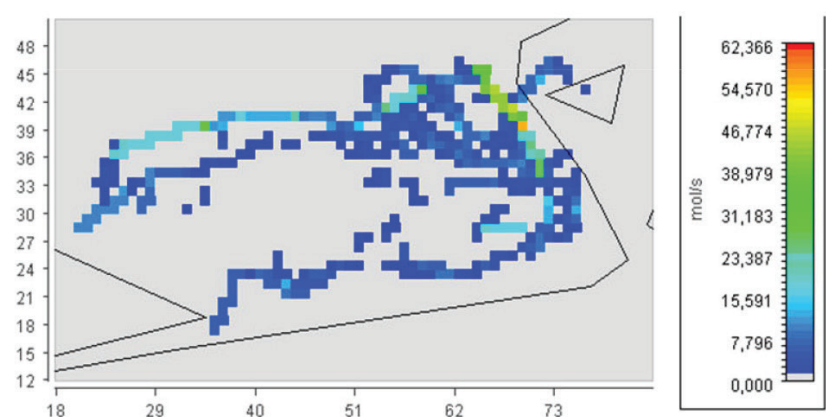

f)

2 de Janeiro de $201322: 00: 00 \mathrm{~h}$

$\operatorname{Min}(18,12)=0,000, \operatorname{Max}(69,39)=54,865$

Figura 5. (a) perfil de CO às $12 \mathrm{~h}$; (b) perfil de CO às $14 \mathrm{~h}$; (c) perfil de CO às $16 \mathrm{~h}$; (d) perfil de CO às $18 \mathrm{~h}$; (e) perfil de CO às $20 \mathrm{~h}$; (f) perfil de CO às $22 \mathrm{~h}$

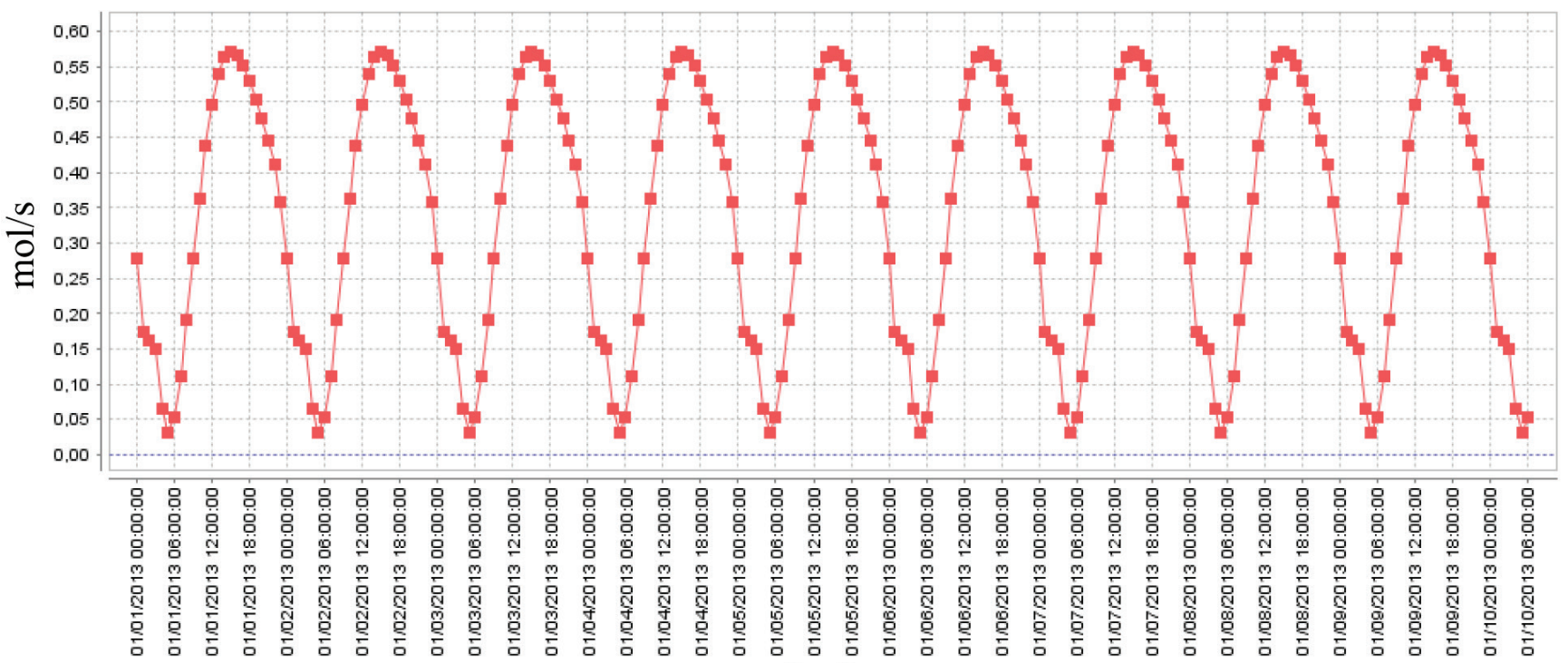

Figura 6. Média Horária de [CO] emitido por fontes veiculares em mol $\mathrm{s}^{-1}$ nas vias inventariadas na cidade do Rio de Janeiro 


\section{REFERENCIAS}

1. Andrade, M. de F.; Kumar, P.; de Freitas, E. D.; Ynoue, R. Y.; Martins, J.; Martins, L. D.; Nogueira, T.; Perez-Martinez, P.; de Miranda, R. M.; Albuquerque, T.; Gonçalves, F. L. T.; Oyama, B.; Zhang, Y.; Atmos. Environ. 2017, 159, 66.

2. Gulia, S.; Shiva Nagendra, S. M.; Khare, M.; Khanna, I.; Atmos. Pollut. Res. 2015, 6, 286.

3. http://www.inea.rj.gov.br/cs/groups/public/@inter_dimfis_gear/ documents/document/zwew/mdgy/ edisp/inea0082534.pdf, acessado em setembro de 2020 .

4. http://www.inea.rj.gov.br/cs/groups/public/@inter/documents/document/ zwew/mti3/ edisp/inea0127421.pdf, acessado em setembro de 2020.

5. Hallquist, M.; Wenger, J. C.; Baltensperger, U.; Rudich, Y.; Simpson, D.; Claeys, M.; Dommen, J.; Donahue, N. M.; George, C.; Goldstein, A. H.; Hamilton, J. F.; Herrmann, H.; Hoffmann, T.; Iinuma, Y.; Jang, M.; Jenkin, M. E.; Jimenez, J. L.; Kiendler-Scharr, A.; Maenhaut, W.; McFiggans, G.; Mentel, T. F.; Monod, A.; Prévôt, A. S. H.; Seinfeld, J. H.; Surratt, J. D.; Szmigielski, R.; Wildt, J.; Atmos. Chem. Phys. 2009, 9, 5155 .

6. Griffin, R. J.; Dabdub, D.; Seinfeld, J. H.; J.of Geoph. Res. Atmos. 2002, 107, 4223.

7. Kroll, J. H.; Seinfeld, J. H.; Atmos. Environ. 2008, 42, 3593.

8. Martins, E. M.; Meireles, A. R.; Magalhaes, F. R.; Carvalho, J. B. B.; Ribeiro, M. M.; Rev. Int. Ciências 2017, 7, 32.

9. Martins, E. M.; Fortes, J. D. N.; Lessa, R. D. A.; Rev. Int. Ciências 2015, 5,2 .

10. Corrêa, S. M.; Arbilla, G.; Martins, E. M.; Quitério, S. L.; de Souza Guimarães, C.; Gatti, L. V.; Atmos. Environ. 2010, 44, 2302.

11. Seinfeld, J. H.; Pandis, S. N.; Atmospheric chemistry and physics: from air pollution to climate change, $3^{\text {rd }}$ ed., John Wiley \& Sons: New York, 2016.

12. Santiago, A. M.; Tese de Doutorado, Universidade Federal do Espírito Santo, Brasil, 2015.

13. Yu, Y.; Sokhi, R. S.; Kitwiroon, N.; Middleton, D. R.; Fisher, B.; Atmos. Environ. 2008, 42, 4870.

14. Geraldino, C. G. P.; Martins, E. M.; da Silva, C. M.; Arbilla, G.; Bull. Environ. Contam. Toxicol. 2017, 98, 632.

15. Silva, D. B. N.; Martins, E. M.; Corrêa, S. M.; Environ. Monit. Assess. 2016, 188, 289.

16. https://www3.epa.gov/ttn/scram/userg/other/ozipr.pdf, acessado em setembro de 2020.

17. Borrego, C.; Amorim, J. H.; Tchepel, O.; Dias, D.; Rafael, S.; Sá, E.; Pimentel, C.; Fontes, T.; Fernandes, P.; Pereira, S. R.; Bandeira, J. M.; Coelho, M. C.; Atmos. Environ. 2016, 131, 341.

18. Yu, M.; Zhu, Y.; Lin, C. J.; Wang, S.; Xing, J.; Jang, C.; Huang, J.; Huang, J.; Jin, J.; Yu, L.; J. Environ. Manage. 2019, 244, 127.

19. Hu, J.; Li, X.; Huang, L.; Ying, Q.; Zhang, Q.; Zhao, B.; Wang, S.; Zhang, H.; Atmos. Chem. Phys. 2017, 17, 13103.

20. Jiang, X.; Yoo, E.; Sci. Total Environ. 2018, 627, 1528.

21. Borge, R.; Lumbreras, J.; Rodríguez, E.; Environmental Modelling \& Software 2008, 23, 1026.

22. Borge, R.; Santiago, J. L.; de la Paz, D.; Martín, F.; Domingo, J.; Valdés, C.; Sánchez, B.; Rivas, E.; Rozas, M. T.; Lázaro, S.; Pérez, J.; Fernández, Á.; Sci. Total Environ. 2018, 635, 1574.

23. Albuquerque, T. T. A.; Andrade, M. F.; Ynoue, R. Y.; Environ. Monit. Assess. 2012, 184, 969.

24. Loriato, A. G.; Salvador, N.; Loriato, A. A. B.; Sokolov, A.; Nascimento, A. P.; Ynoue, R. Y.; Moreira, D. M.; Reis, N. C.; Albuquerque, T. T. A.; Rev. Bras. Meteorol. 2018, 33, 521.

25. Pedruzzi, R.; Baek, B. H.; Henderson, B. H.; Aravanis, N.; Pinto, J. A.; Araujo, I. B.; Nascimento, E. G. S.; Reis Junior, N. C.; Moreira, D. M.; Albuquerque, T. T. A.; Environ. Sci. Pollut. Res. 2019, 26, 16125.
26. Yang, X.; Wu, Q.; Zhao, R.; Cheng, H.; He, H.; Ma, Q.; Wang, L.; Luo, H.; Atmos. Environ. 2019, 211, 18.

27. https://www.cmascenter.org/cmaq/science_documentation/pdf/ch11.pdf, acessada em setembro de 2020 .

28. https://opensky.ucar.edu/islandora/object/opensky:2898, acessado em setembro de 2020.

29. https://www.cmascenter.org/smoke/documentation/4.5/manual_ smokev45.pdf, acessado em setembro 2020.

30. Li, X.; Rappenglück, B.; Atmos. Environ. 2014, 97, 363.

31. Seaman, N. L.; Atmos. Environ. 2000, 34, 2231.

32. Carvalho, V. S. B.; Freitas, E. D.; Mazzoli, C. R.; Andrade, M. F. Rev. Bras. Meteorol. 2012, 27, 463.

33. Bieser, J.; Aulinger, A.; Matthias, V.; Quante, M.; Builtjes, P.; Geosci. Model Dev. 2011, 4, 47.

34. Bowden, J. H., Otte T. L., Nolte C. G., Otte A. M. ; J. Clim. 2012, 28, 2805.

35. Harris, L. M.; Durran, D. R.; Mon. Weather Rev. 2010, 138, 2174.

36. Albuquerque, T. T. A.; Andrade, M. F.; Ynoue, R. Y.; Moreira, D. M.; Andreão, W. L.; Santos, F. S.; Nascimento, E. G. S.; Environ. Sci. Pollut. Res. 2018, 25, 36555.

37. Mlawer, E. J.; Taubman, S. J.; Brown, P. D.; Iacono, M. J.; Clough, S. A.; J. Geophys. Res. Atmos. 1997, 102, 16663.

38. Dudhia, J.; J. Atmos. Sci. 1989, 46, 3077.

39. Hicks, B. B.; Dyer, A. J.; Q. J. R. Meteorol. Soc. 1970, 96, 523.

40. Chen, F.; Dudhia, J.; Mon. Weather Rev. 2001, 129, 569.

41. Hong, S. Y.; Noh, Y.; Dudhia, J.; Mon. Weather Rev. 2006, 134, 2318.

42. Kain, J. S.; Kain, J.; J. Appl. Meteorol. 2004, 43, 170.

43. https://rda.ucar.edu/datasets/ds093.0, acessado em setembro de 2020.

44. http://www.data.rio/datasets/estações-de-monitoramento-da-qualidadedo-ar-monitorar/geoservice, acessado em setembro de 2020.

45. http://www.inea.rj.gov.br/ar-agua-e-solo/monitoramento-da-qualidadedo-ar-e-meteorologia, acessado em setembro de 2020.

46. https://www3.epa.gov/ttn/scram/guidance/guide/O3-PM-RH-Modeling Guidance-2018.pdf, acessado em setembro de 2020.

47. Itahashi, S.; Mathur, R.; Hogrefe, C.; Zhang, Y.; Atmos. Chem. Phys. 2020, 20, 3373 .

48. Hogrefe, C.; Pouliot, G.; Wong, D.; Torian, A.; Roselle, S.; Pleim, J.; Mathur, R.; Atmos. Environ. 2015, 115, 683.

49. Mathur, R.; Xing, J.; Gilliam, R.; Sarwar, G.; Hogrefe, C.; Pleim, J.; Pouliot, G.; Roselle, S.; Spero, T.; Wong, D.; Young, J.; Atmos. Chem. Phys. 2017, 17, 12449.

50. Zhang, Y.; Liu, P.; Pun, B.; Seigneur, C.; Atmos. Environ. 2006, 40, 4825.

51. Diao, L.; Choi, Y.; Czader, B.; Li, X.; Pan, S.; Roy, A.; Souri, A. H.; Estes, M.; Jeon, W.; Atmos. Res. 2016, 181, 257.

52. Willmott, C. J.; Robeson, S. M.; Matsuura, K.; Int. J. Climatol. 2012, $32,2088$.

53. Wong, D. C.; Pleim, J.; Mathur, R.; Binkowski, F.; Otte, T.; Gilliam, R.; Pouliot, G.; Xiu, A.; Young, J. O.; Kang, D.; Geosci. Model Dev. 2012, 5, 299.

54. https://www.cmascenter.org/cmaq/science_documentation, acessado em setembro de 2020.

55. https://github.com/USEPA/CMAQ/blob/master/DOCS/Users_Guide/ PDF/CMAQ_UG_09_2019.pdf, acessado em setembro de 2020.

56. Vilella, A. C. S.; Sá, R. A. B.; Vicentini, P. C.; Carvalho, R. N.; Machado, G. B.; de Melo, T. C. C.; Silva, K. M.; Blucher Engineering Proceeding (XXIII Simpósio Internacional de Engenharia Automotiva) 2015, 2, 449.

57. https://www.qgis.org/pt_BR/site, acessado em setembro de 2020.

58. Geraldino, C. G. P.; Dissertação de Mestrado, Universidade do Estado do Rio de Janeiro, Brasil, 2017.

59. https://intra.engr.ucr.edu/ carter/pubs/s99doc.pdf, acessado em setembro de 2020. 